\title{
CONTROVÉRSIAS E BINARISMOS: CONCEPÇÕES DE PROFESSORAS SOBRE BRINCADEIRAS E GÊNERO NA EDUCAÇÃO INFANTIL
}

\author{
Luciane Cristina Corrêa \\ (Secretaria de Educação do Município de Lages)* \\ Mareli Eliane Graupe (UNIPLAC)** \\ http://orcid.org/0000-0001-5489-1361 \\ Regina Ingrid Bragagnolo (UFSC) ${ }^{* * *}$ \\ http://orcid.org/0000-0002-8237-7383
}

\begin{abstract}
RESUMO
Este artigo tem como objetivo analisar as concepções de gênero e de brincadeiras de professoras de Educação Infantil de uma cidade do interior do Sul do Brasil. 0 referencial teórico abarca autores(as) como Butler (1990), Meirelles (2015), Campos e Barbosa (2015), Kishimoto (2008), Finco (2003) e Louro (2014). A pesquisa é de cunho qualitativo e teve como registro metodológico entrevistas focalizadas com cinco docentes e observação participante passiva. Os dados apontam que o debate de gênero na Educação Infantil apresenta controvérsias e ambivalências, na concepção das professoras, ao tratar das brincadeiras e gênero na medida que fazem uso de uma ordem conceitual pautada nos binarismos: entre meninos e meninas, nos brinquedos e brincadeiras e nos modos de organização dos corpos nos espaços educativos. Desse modo, a ampliação da produção de conhecimentos no campo de estudos de gênero e educação infantil é urgente e necessária.
\end{abstract}

Palavras-chave: educação infantil; brincadeiras; gênero; binarismos.

\section{ABSTRACT \\ CONTROVERSIES AND BINARISMS: TEACHERS' CONCEPTIONS ABOUT PLAY AND GENDER IN EARLY CHILDHOOD EDUCATION \\ This article aims to analyze the conceptions of gender and play of teachers of early}

\footnotetext{
Mestre em Educação pela Universidade do Planalto Catarinense (UNIPLAC). Professora de Educação Infantil na Secretaria de Educação do Município de Lages. Lages, Santa Catarina, Brasil. E-mail: lucianecorrea1979@gmail.com

** Pós-doutora pelo Programa Interdisciplinar em Ciências Humanas e pelo Programa de Antropologia Social da Universidade Federal de Santa Catarina (UFSC). Doutora em Educação e Cultura pela Universidade de Osnabrueck, Alemanha. Professora do Programa de Pós-Graduação em Educação e do Programa de Pós-Graduação em Ambiente e Saúde na Universidade do Planalto Catarinense (UNIPLAC). Coordena o grupo de pesquisa Gênero, Educação e Cidadania na América Latina (GECAL/ UNIPLAC). E-mail: prof.mareli@uniplaclages.edu.br

*** Doutora em Psicologia pela Universidade Federal de Santa Catarina (UFSC) e professora no Núcleo de Desenvolvimento Infantil (NDI/UFSC). Florianópolis, Santa Catarina, Brasil. E-mail: ingridbragagnolo@gmail.com
} 
childhood education in a city in the south of Brazil. The theoretical framework encompasses authors such as: Butler (1990), Meirelles (2015), Campos \& Barbosa (2015), Kishimoto (2008), Finco (2003), Louro (2014), among others. This qualitative research had as methodological record focused interviews with five teachers and passive participant observation. The data indicate that the gender debate in early childhood education presents controversies and ambivalences, in the teachers' conception, when dealing with play and gender, as they make use of a conceptual order based on binarisms: binarisms between boys and girls, binarisms in toys and games and binarisms in the modes of organization of bodies in educational spaces. Thus, the expansion of knowledge production in the field of gender studies and early childhood education is urgent and necessary.

Keywords: early childhood education; play; gender; binarisms.

\section{RESUMEN}

\section{CONTROVERSIAS Y BINARISMOS: CONCEPCIONES DEL PROFESOR EN JUEGOS INFANTILES Y GÉNERO EN LA EDUCACIÓN INFANTIL}

Este artículo tiene como objetivo analizar las concepciones de género y juegos infantiles de los docentes de educación infantil en una ciudad del sur de Brasil. El marco teórico abarca autores como: Butler (1990), Meirelles (2015), Campos y Barbosa (2015), Kishimoto (2008), Finco (2003) y Louro (2014). La investigación es cualitativa y tuvo como registro metodológico entrevistas enfocadas con cinco maestros y observación pasiva participante. Los datos indican que el debate de género en la educación de la primera infancia presenta controversias y ambivalencias, en la concepción de los maestros, cuando se trata de juegos y género, ya que hacen uso de un orden conceptual basado en binarismos: entre niños y niñas, sobre juguetes y juegos y en los modos de organización de los cuerpos en espacios educativos. Por lo tanto, la expansión de la producción de conocimiento en el campo de los estudios de género y la educación de la primera infancia es urgente y necesaria.

Palabras clave: educación de la primera infância; juegos infantiles; género; binarismo.

\section{Introdução ${ }^{1}$}

Quais são os discursos de gênero presentes nas práticas pedagógicas de professoras ${ }^{2}$ de

1 Este artigo é resultado de um projeto de pesquisa que foi aprovado pelo Comitê de Ética e Pesquisa da universidade das pesquisadoras.

2 Opta-se por utilizar professora no feminino neste artigo, por se tratar de uma pesquisa realizada com mulheres que atuam na Educação Infantil. Importante explicitar que se considera importante todo debate e interlocução dos Estudos de Gênero no campo da Educação Infantil em considerar necessário nomear e valorar professores, sobretudo por ter-se historicamente naturalizado o papel da mulher como docente de crianças pequenas e toda
Educação Infantil? O que as professoras estão fazendo no cotidiano da prática pedagógica quando tratamos de relações de gênero? Quais estratégias metodológicas educativas estão sendo estabelecidas pelas professoras nas brincadeiras? Quais esforços têm sido realizados para romper com os binarismos, os estereótipos e as desigualdades de gênero? Com essas

repercussão política, histórica e salarial decorrente dessa concepção. 
perguntas, inicia-se o presente artigo, que tem como objetivo analisar as construções de gênero nos momentos das brincadeiras de um Centro de Educação Infantil de uma instituição pública do estado de Santa Catarina. Assim sendo, tem-se intenção de suscitar debates sobre a consolidação e valoração, ou mesmo das discrepâncias da categoria gênero e seus desdobramentos no cotidiano educacional, sobretudo ao observar nas narrativas das professoras o debate sobre os binarismos de gênero.

Nos valemos das críticas de Butler (1990) para pensar nos binarismos de gênero, pois essa autora insiste no debate sobre o modo como se constitui um sistema de gênero a partir do sexo, e como este começa a parecer inato e natural. Com suas contundentes críticas às discussões de gênero, Butler (1990) renovou o olhar sobre o conceito de gênero, trazendo para a cena as implicações e barreiras das normas discursivas.

Inicia-se o artigo com uma breve revisão de gênero na Educação Infantil, voltando o olhar para as especificidades dos discursos que ancoram o debate sobre as brincadeiras, objetivando situar um conjunto de reflexões sobre práticas, políticas e saberes que compõem o cotidiano das creches e, de algum modo, apontam ao/à leitor(a) as opções teóricas deste estudo. Por ora, sinteticamente são reunidos alguns dos principais elementos que caracterizaram a pesquisa: definição de infância, brincadeiras e gênero na Educação Infantil.

Parte-se do pressuposto de que as crianças são sujeitos de direitos que, em termos educacionais, devem ter asseguradas as condições para construírem conhecimentos, partilharem saberes, fazerem escolhas e expressarem sua individualidade e seus sentimentos (BRASIL, 2010).

Encontramos essas definições em inúmeros documentos que integram as discussões sobre a educação infantil, destacando, aqui, as Diretrizes Curriculares Nacionais para a Educação Infantil (BRASIL, 2010), por demarcar que a Educação Infantil no contexto nacional é com- preendida como primeira etapa da educação básica, direcionada para crianças de zero a cinco anos e onze meses, percebendo a criança como sujeito que constrói sua identidade por meio de práticas cotidianas permeadas pelas brincadeiras e interações sociais. Assegurando uma educação pública qualificada e garantida pelo Estado, define-se Educação Infantil como:

Primeira etapa da educação básica, oferecida em creches e pré-escolas, às quais se caracterizam como espaços institucionais não domésticos que constituem estabelecimentos educacionais públicos ou privados que educam e cuidam de crianças de 0 a 5 anos de idade no período diurno, em jornada integral ou parcial, regulados e supervisionados por órgão competente do sistema de ensino e submetidos a controle social. (BRASIL, 2010, p. 12).

Segundo Finco, Gobbi e Faria (2015), a luta pela implementação e expansão da creche e pré-escola foi uma luta feminista, visando a garantia da igualdade de direitos para homens e mulheres, por meio da participação da mulher na vida profissional.

A Educação Infantil como direito social, como política pública educativa, é resultado de um intenso e longo processo de lutas, no qual os movimentos sociais, sobretudo os feministas, foram grandes protagonistas. De modo diferente do ensino fundamental, a educação infantil teve um percurso peculiar, o qual para ser compreendido deve ser discutido não apenas sob a perspectiva de uma 'história únca', pois é preciso considerar todas as lutas, os debates, as disputas e discussões referentes ao papel da mulher e da família, a divisão sexual do trabalho, a igualdade de direitos entre homens e mulheres e o direito das crianças. (CAMPOS; BARBOSA, 2015, p. 354, grifo do autor).

Vale lembrar que a criação das instituições de Educação Infantil no Brasil foi o ponto central da análise de Kramer (2011). Essa autora problematiza que muito embora tenha havido avanços no campo jurídico e normativo, dado a conquista e o reconhecimento da Educação Infantil na Constituição Federal de 1988 (BRASIL, 1988), a crítica à concepção de infância na perspectiva de uma criança 
universal, concebida como um modelo padrão pelas classes dominantes, ainda necessita ser problematizada. Ademais, se torna importante refletir sobre a concepção de infância atrelada à noção de incompletude, bem como concepções adultocêntricas em torno das infâncias. Ao reler os registros históricos da Educação Infantil no Brasil, percebe-se que as noções de risco e vulnerabilidade na infância serviram, inclusive, para a própria legalização da Educação Infantil. Assim sendo, o lugar das crianças nas instituições também surge para assegurar a elas um espaço de segurança e proteção.

\section{Brinquedos, brincadeiras nos horizontes de gênero}

Ao tratar das relações de gênero nas brincadeiras na Educação Infantil, opta-se neste estudo por incorporar reflexões sobre o percurso de movimentos sociais de mulheres e feministas para garantir o direito das famílias e crianças a espaços institucionais e, por conseguinte, levar em conta a importância do modo como se deu o debate de gênero, tendo em vista que a própria construção dessa categoria traz elementos para compreender por que, histórica e socialmente, os lugares reconhecidos para homens e mulheres geram desigualdades.

Desse modo, para a compreensão do conceito de gênero, utilizou-se neste artigo as discussões de Guacira Lopes Louro (2014), Claúdia Vianna (2011) e Daniela Finco (2003). Nesse sentido, nas palavras de Finco (2003), a própria categoria de gênero foi construída socialmente sobre as diferenças entre homens e mulheres, percebidas em distintas culturas. Em virtude disso, ressalta essa autora que: "O conceito de gênero implica conhecer, saber mais sobre as diferenças sexuais e seus significados. Compreender como são produzidas, pelas culturas e sociedades, as diferenças nas relações entre homens e mulheres" (FINCO, 2003, p. 91).

Em se tratando do debate de gênero, faz-se importante, em primeira instância, situar as contribuições históricas do lugar da mulher e as desigualdades de gênero, por colocar-se também os grandes desafios da atualidade na prática pedagógica. A análise do ocultamento das mulheres e as lutas de resistência contrárias à condição de submissão no decorrer do século XX no Brasil, segundo Louro (2014), proporcionam uma reflexão sobre as desigualdades de gênero que, aos poucos, foram naturalizadas por meio da cultura ocidental.

Ao final do século XIX e começo do século XX, as lutas feministas, segundo a autora, eram mais voltadas ao direito das mulheres ao voto, acesso igualitário na escolha profissional, oportunidade de trabalho, questionando também a forma de organização familiar. Será no desdobramento da assim denominada 'Segunda onda' - aquela que se inicia no final da década de 1960 - que o feminismo, além das preocupações sociais e políticas, irá se voltar para as construções propriamente teóricas. (LOURO, 2014, p. 19).

As preocupações teóricas de Louro (2014) vão além da expansão do espaço profissional feminino restrito ao ambiente doméstico. A formação de revistas e grupos organizados a partir de diferenciados interesses desempenham papel importante nesses estudos, questionando o referencial masculino e reconhecendo a mulher como autora da própria história.

França, Estados Unidos, Inglaterra, Alemanha, são locais especialmente notáveis para observarmos intelectuais, estudantes, negros, mulheres, jovens, enfim, diferentes grupos que, de muitos modos, expressam sua inconformidade e desencanto em relação aos tradicionais arranjos sociais e políticos, às grandes teorias universais, ao vazio formalismo acadêmico, à discriminação, à segregação e ao silenciamento. (LOURO, 2014, p. 20).

Nessa direção, historicamente, os papéis desenvolvidos por homens e mulheres foram discursivamente definidos/atrelados às características biológicas. Em se tratando de educação de crianças pequenas, essa concepção generificada ganha lugar, por acreditar-se que mulheres são naturalmente aptas para cuidar de crianças. ${ }^{3}$

3 0 autor Jean-Jacques Rousseau inaugura o discurso de que a mulher, pelo fato de ser mãe, é naturalmente apta a educar 
Encontramos contundentes reflexões no âmbito da educação, especialmente no artigo "Gênero: uma categoria útil de análise histórica", publicado no Brasil em 1990 (e corrigido em 1995), da historiadora Joan Scott (1995), por trazer em primeiro plano contribuições para os estudos de gênero, sobretudo por permitir entender como historicamente se produziram as diferenças sexuais e, decorrente disso, os desdobramentos dessas representações nos espaços institucionais.

Nessa perspectiva, Vianna (2011), por meio da análise sobre as construções sexuais, oriundas de explicações biológicas, questiona as naturalizações acerca dos papéis atribuídos a cada sexo.

No campo conceitual de Educação Infantil, Finco (2003) questiona como as relações entre as crianças podem determinar papéis para meninos e meninas, apontando as expectativas dos adultos acerca desses papéis. Tais representações são questionadas por Kishimoto (2008), ao analisar como os brinquedos são organizados e oferecidos para cada sexo. Essa autora descreve como a forma de organização dos brinquedos proporciona momentos de aprendizagem, favorecendo a diversidade e a identidade. Neste sentido, Meirelles (2015) promove uma articulação entre o brincar e as ações das professoras, por meio de um documentário que explicita pesquisa realizada em diferentes regiões do Brasil, construindo uma concepção do brincar pelo olhar da criança.

\footnotetext{
as crianças pequenas, como podemos observar na citação a seguir: "A educação primeira é a que mais importa, e essa primeira educação cabe incontestavelmente às mulheres: se o Autor da natureza tivesse querido que pertencesse aos homens, ter-lhes-ia dado leite para alimentarem as crianças. Falarei, portanto, às mulheres, de preferência, em vossos tratados de educação; pois além de terem a possibilidade de para isso atentar mais de perto que os homens, e de nisso influir cada vez mais, o êxito as interessa também muito mais, porquanto em sua maioria as viúvas se acham quase à mercê de seus filhos e que então precisam sentir, em bem ou mal, o resultado da maneira pela qual os educaram. As leis, sempre tão preocupadas com os bens e tão pouco com as pessoas por terem como objetivo a paz e não a virtude, não outorgam suficiente autoridade às mães." (ROUSSEAU, 1995, p. 9-10).
}

Esse processo de olhar, refletir e dialogar baseado naquilo que nos ensinavam as crianças fortaleceu em todos nós aspectos que foram muito além dos educacionais, e frutificou crenças que já habitavam os recônditos de nossos desejos. Somos seres plenos de vida e não podemos deixar que nos distraiam disso. É preciso estar no presente, no aqui e agora, para conseguir escutar a criança e, consequentemente, a nós mesmos. (MEIRELLES, 2015, p. 21).

No que tange às brincadeiras, é importante compreender por que se tornaram um eixo norteador curricular, conforme descrito nas Diretrizes Curriculares da Educação Infantil (BRASIL, 2010) e constituíram-se como base para a realização das práticas elaboradas a partir de propostas pedagógicas. Ainda, nesse documento encontra-se um aspecto importante que diz respeito às diferentes identidades e à diversidade, como princípios éticos, estéticos e políticos que poderão embasar as propostas pedagógicas da Educação Infantil. Conforme este documento, a Educação Infantil possui como foco o cuidar e o educar. Educar a criança para todas as transformações que ocorrem gradativamente em nossa sociedade, tornando-se essencial uma educação na qual as práticas pedagógicas possibilitem à criança uma formação mais humanizada no que diz respeito às diferenças. Formação esta, cabe lembrar, embasada em princípios de tolerância e solidariedade. Com base nesse documento, as instituições de Educação Infantil, dentre seus objetivos, devem garantir a socialização e o reconhecimento das diferenças por meio das vivências e brincadeiras. Assim, as crianças que frequentam as instituições de Educação Infantil terão oportunidade de se relacionar com adultos e com outras crianças, o que se constitui como experiência formativa dos sujeitos, vindo a contribuir para uma convivência pautada no respeito à diversidade humana.

Contemporaneamente, os desdobramentos de gênero nas propostas curriculares tornaram-se desafios, pois implicam tensionamentos e disputas, emergindo novas e velhas polêmicas no cenário político nacional. Nesse sentido, 
encontramos em Carreira (2016) argumentos interessantes sobre o movimento contemporâneo de resistência de diferentes instituições e grupos religiosos conservadores, causando retrocessos na criação de políticas públicas de gênero.

Segundo Carreira (2016), diante do contexto de redução de investimentos, ruptura de programas e contratos voltados às políticas públicas de gênero, houve aumento significativo desses desafios. Movimentos como o Programa Escola sem Partido e grupos religiosos disseminam conceitos contrários à implementação dessas políticas. Diante dos embates políticos da atualidade, organizações tais como o Comitê da América Latina e do Caribe para a Defesa da Mulher (CLADEM), o Instituto da Mulher Negra (GELEDÉS) e a Ação Educativa e Comunicação em Sexualidade (ECOS) destacam a importância da ampliação dos debates para um fortalecimento das alianças para a igualdade de gênero nas políticas educacionais, as quais impactam diretamente no cotidiano escolar e social. "É fundamental construir e atravessar 'pontes', além de somar forças com todas e todos aqueles comprometidos com democracia, justiça social e direitos humanos no país." (CARREIRA, 2016, p. 12).

No Informe Brasil - Gênero e Educação ${ }^{4}$ (CARREIRA, 2011) são expostos os desafios perante a equidade de gênero que, no parecer do Estado brasileiro, estão solucionados, em resposta a uma maior atuação no campo escolar para atender às metas internacionais.

O citado Informe apresenta definições necessárias à inclusão da equidade de gênero nas políticas educacionais. Neste caso, entende-se gênero como categoria de análise diante das construções fundamentadas sobre as diferenças entre homens e mulheres, marcadas pelas relações de poder. Ao refletir sobre o direito à educação, há alguns aspectos a serem levados

4 "Lançado em 2011 e atualizado em 2013, o Informe foi produzido no marco da campanha por uma Educação Não-Sexista e Antidiscriminatória promovida pelo Comitê Latino-Americano e do Caribe para a Defesa dos Direitos da Mulher (CLADEM)" (CARREIRA, 2016, p. 26). em consideração, cuja presença é um sinalizador da garantia desse direito: espaço físico adequado, melhores salários aos professores, acesso não limitado e não discriminatório nas instituições de ensino, projeto pedagógico que contemple igualdade de direitos e um ambiente flexível aos diferentes contextos sociais.

Perante alguns desafios destacados no Informe Brasil - Gênero e Educação (CARREIRA, 2011), Carreira (2016) relata obstáculos comuns ao ser abordada a temática gênero na educação brasileira, fazendo suas constatações segundo o Instituto Brasileiro de Geografia e Estatística (IBGE) e o Instituto Nacional de Estudos e Pesquisas Educacionais Anísio Teixeira (INEP). Tais organizações explicitam formas de desigualdade em todos os setores da sociedade civil, consequências de uma histórica educação discriminatória, sexista e pouco reconhecimento das carreiras definidas como femininas. Aponta também como as políticas públicas e os programas sociais voltados à igualdade de direitos passam por uma fase de retrocessos. $\mathrm{Na}$ divulgação do Informe atualizado, as organizações responsáveis pelo documento cobraram que o governo federal reagisse à onda conservadora, continuasse os programas e políticas conquistados na última década e defendesse ativamente o princípio de laicidade do Estado na educação pública (CARREIRA, 2016).

Nessa perspectiva, é importante destacar que a formação continuada das professoras, segundo Carreira (2016), ainda não contempla conteúdos voltados à igualdade de gênero e diversidade. Mesmo que existam programas no Ministério da Educação, é necessário consolidá -los como política pública de Estado, ampliando para políticas necessárias à formação profissional. Desse modo, emergem ações para desconstrução da naturalização de profissões corretas para homens e mulheres. "Esta transformação exige ações que vão desde a educação infantil ao ensino superior." (CARREIRA, 2016, p. 41).

Por fim, a recomendação mais importante do Informe Brasil - Gênero e Educação (CARREIRA, 2011) é promover um movimento mobilizador 
acerca da implementação do Plano Nacional de Educação (PNE) efetivando, juntamente com suas metas, a expansão do atendimento educacional e a melhoria da qualidade de vida. Em relação ao PNE, Reis e Eggert (2017, p. 15) apontam:

A proposta do novo PNE foi apresentada na Câmara dos Deputados em 20 de dezembro de 2010. Após quase dois anos de debates e tramitação, a redação final aprovada pela Câmara dos Deputados e encaminhada para o Senado contemplou as deliberações das Conferências Nacionais de Educação sobre equidade de gênero e o respeito à diversidade sexual de duas formas principais.

O Plano Nacional de Educação (PNE) foi aprovado em 26 de junho de 2014, pela Lei $\mathrm{n}^{\circ}$ 13.005 (BRASIL, 2014), e possui validade de dez anos. Neste Plano, foi excluída a palavra equidade de gênero e o mesmo aconteceu nos planos estaduais de educação. Conforme Reis e Eggert (2017, p. 18),

[...] em relação aos 22 dos 27 Planos Estaduais de Educação aprovados e sancionados na forma de lei, 9 não fazem qualquer referência à palavra 'gênero' e 15 não explicitam o termo 'gênero' nos Princípios ou Diretrizes do Plano ao citar o enfrentamento a toda forma de discriminação.

As pressões realizadas pelos grupos políticos fundamentalistas, além da exclusão da palavra gênero e diversidade sexual nos planos nacional e estaduais, conseguiram extinguir o Comitê de Gênero, ${ }^{5}$ que foi instituido conforme Portaria no 916/2015 (REIS; EGGERT, 2017). Este comitê teria o objetivo de apontar diretrizes e subsídios para a garantia de direitos educacionais, por meio de ações e projetos, objetivando a superação dos preconceitos e violência. "Mediante pressão da Câmara dos Deputados à Presidência da República, em um

5 "O presente documento tem como objetivo principal disponibilizar orientações que sirvam à institucionalização desses mecanismos de gênero. Seu principal subsídio foram os resultados da Oficina sobre os Comitês de Gênero nos Ministérios, realizada em 19 de maio de 2010, no âmbito da $34^{a}$ Reunião Ordinária do Comitê de Articulação e Monitoramento do Plano Nacional de Políticas para as Mulheres - PNPM." (BRASIL, 2011, p. 12). espaço de apenas 12 dias, o Comitê de Gênero foi extinto e substituído por um Comitê de Combate à Discriminação." (REIS; EGGERT, 2017, p. 19).

Para articular a importância da discussão dessas políticas de gênero e educação, Louro (2014) destaca a contextualização dos sujeitos resultante de uma cultura ocidental, circunstância em que emerge a necessidade da ampliação do olhar desconfiado nas práticas cotidianas e na forma de organização do ambiente escolar. Neste artigo, o foco está no contexto das brincadeiras e interações na Educação Infantil.

\section{Metodologia}

Neste estudo, o embasamento teórico-metodológico permitiu elaborar uma pesquisa de cunho qualitativo, compreendendo a pluralidade de pensamentos que, segundo Flick (2009), se dá a partir de conceitos sensibilizantes. Para esse autor, na pesquisa qualitativa, o objeto torna-se o motivo determinante da seleção do método, levando em conta as perspectivas dos participantes e sua diversidade.

Desse modo, realizamos a pesquisa empírica em um Centro de Educação Infantil no estado de Santa Catarina. Foram entrevistadas cinco professoras que atuam na pré-escola da referida instituição, por meio de entrevista focalizada, com roteiro semiestruturado, conforme os conceitos de Flick (2009). Além das entrevistas focalizadas, foi realizada observação participante passiva com a finalidade de responder à problemática da pesquisa. Os dados foram analisados segundo a análise de conteúdo qualitativo de Mayring (2007), pela técnica de análise explicativa.

Para realização das entrevistas, primeiramente foi solicitado à direção da instituição de Educação Infantil a autorização para pesquisa de campo. A equipe diretiva deste Centro de Educação Infantil é composta por uma Gestora, uma Auxiliar de Direção e uma Técnica Educacional. Dentre as participantes da entrevista, 
incluem-se uma professora identificada como Penélope, ${ }^{6} 36$ anos, gênero feminino, casada, duas filhas, espírita/católica, graduação em Pedagogia e especialização em Psicopedagogia e Gestão Escolar. A segunda participante, identificada como Lolita, é casada, 29 anos, gênero feminino, um filho, católica, com licenciatura plena em Pedagogia e especialização em Práticas Interdisciplinares em Educação Especial e Práticas Inclusivas. A terceira participante, identificada como Atena, casada, 42 anos, gênero feminino, católica, um filho e duas filhas, graduada em Pedagogia e com especialização em Educação Especial. A quarta participante, identificada como Shena, é casada, 33 anos, gênero feminino, duas filhas, espírita, graduação em Pedagogia e especialização em Interdisciplinaridade e Gestão Escolar. Por fim, a última participante, identificada como Anitta Garibaldi, casada, 44 anos, gênero feminino, duas filhas, católica, com graduação em Pedagogia e especialização em Psicopedagogia.

Enfatizamos que todas as professoras aceitaram, gentilmente, contribuir com a pesquisa. A receptividade da equipe de direção e o empenho em proporcionar o espaço e tempo de qualidade para as entrevistas atendeu às expectativas, tornando esse momento acolhedor e rico nas situações de relatos de experiências.

Para uma coleta de dados mais precisa e detalhada, durante o período da observação participante passiva, que ocorreu no mês de abril de 2018 (em torno de 20 horas de observação), fez-se necessário o registro de todos os momentos em diário de campo. Isso porque, o diário "[...] serve como uma agenda cronológica do trabalho de pesquisa. Além dessa ajuda, deverão ser registradas com exatidão e muito cuidado as observações, percepções, vivências e experiências obtidas na pesquisa." (BARROS, 2007, p. 105). Por essa razão, foram realizadas anotações no diário de campo sobre as entrevistas focalizadas.

60 nome fictício foi escolhido pelas participantes da pesquisa, seguindo o critério de escolher o nome de uma mulher que consideram sinônimo de empoderamento, podendo ser uma personagem, uma heroína etc.

\section{Binarismos: olhares sobre as brincadeiras e relações de gênero no cotidiano}

As controvérsias entre os binarismos de gênero continuam alimentando instigantes discussões e debates no campo da educação. Aqui, trata-se de sistematizar os olhares das professoras entrevistadas sobre as brincadeiras e gênero e seus atravessamentos no campo da Educação Infantil a partir de três eixos inter -relacionados: binarismos atribuídos à diferenciação de meninos e meninas, binarismos nos brinquedos e brincadeiras e binarismos nos modos de organização dos corpos nos espaços educativos.

No presente estudo, opotamos por pensar, a partir de Butler (1990), as categorias descritas atreladas aos binarismos, cuja marca de gênero está assinalada pelo corpo/sexo. Nesse sentido, quando uma menina se identifica com algum brinquedo considerado pertencente a meninos, não deseja ser um menino, mas muitos olhares e discursos reduzem a transgressão de uma norma heteronormativa. Nas palavras de Butler (1990, p. 25), “[...] o gênero não está para a cultura como o sexo para a natureza; ele também é o meio discursivo/cultural pelo qual 'a natureza sexuada' ou 'um sexo natural' é produzido e estabelecido como 'pré-discursivo', anterior à cultura". Para isso, destacamos as interpretações feministas dessa autora sobre esse sistema binário que estabelece lugares, brinquedos, adereços diferentes para meninos e meninas e permite, também, a existência de lógicas excludentes, dicotômicas e hierarquizadas entre si.

Compreender tal crítica, na esteira de Butler (1990), significa ampliar teoricamente a concepção de gênero, pensando aqui os espaços de Educação Infantil enquanto lugares abertos a múltiplas fronteiras. Abordar suas críticas, sobretudo os efeitos discursivos e os processos de subjetivação de meninos e meninas, significa comprometer-se com os desdobramentos do debate de gênero enquanto ferramenta 
importante nas mediações em brincadeiras e organizações de espaços e materiais no cotidiano da Educação Infantil.

\section{Binarismos atribuídos à diferenciação de meninos e meninas}

Em primeiro lugar, faz-se importante registrar que no campo pesquisado foi possível compreender, através da narrativa das professoras, que, de certa forma, a formação incipiente torna-se uma barreira à abordagem de gênero na Educação Infantil. Quando questionadas a respeito do percurso formativo, na maioria das vezes, as participantes fizeram uma pausa, na tentativa de recordar se a temática havia sido abordada nos cursos de formação:

Eu tive, há pouco tempo atrás, uma formação, lá na... na... no congresso, que as meninas foram falar sobre isso, sobre gênero lá... tá ok... mas formação é a única até hoje... Acadêmica, formação continuada na secretaria... não... não? Foi a única. Tá ok... Então a única foi no Congresso da Educação... Isso. (LOLITA).

Sim... há alguns anos atrás, veio uma palestrante... no Congresso da Educação... agora não me recordo o nome da palestrante... só lembro que ela falou muito sobre gênero, na época eu e minhas colegas ficamos chocadas [risos], mas depois com as minhas vivências fui entendendo melhor... (ATENA).

Não lembro também... mas eu sei que teve. E ela falou realmente que existe, agora não vou lembrar quantos, mas existe 200 formas de gênero, eu sei que era um valor absurdo assim, sabe, nossa, eu não conheço tudo isso! Eu fiquei abismada, mas será que tem tudo isso? Eu conheço os gays, lésbicas, homossexual, trans e tal, e comecei a pensar, não passava de dez o que eu conhecia, né? Daí ela falou não lembro o quanto, mas, nossa, é tanto assim, né? Eu disse: 'Tenho que começar a buscar mais, porque eu não sei [risos], tenho que conhecer, né?' (SHENA).

Essas profissionais revelam poucas oportunidades de formação continuada com temáticas acerca das relações gênero e educação.
De acordo com as observações realizadas no campo da pesquisa, constatamos que o conceito de gênero para as professoras e equipe diretiva estava atrelado ao aspecto binário de categorias feminino e masculino, contido nas explicações biológicas.

Para Vianna e Unbehaun (2004), historicamente o conceito de gênero foi construído como atribuição de masculino e feminino, geralmente compreendido como classificação do sexo. Contudo, percebemos que estas construções refletem até hoje nas concepções das entrevistadas, que ainda demonstram um certo estranhamento quando se deparam com teorias que consideram gênero como uma construção social.

Ao retomar a historiografia, encontramos registros no Brasil colonial de papéis atribuídos aos meninos no início da colonização portuguesa. A chegada dos jesuítas ao Brasil, com o intuito de estabelecer a fé cristã, e a dificuldade de conversão dos adultos representou a percepção de que, por meio da evangelização dos meninos, havia um caminho para doutrinação, a fim de estabelecer virtudes que abominariam os costumes dos pais, segundo Ramos (2015). Em relação à educação entre as crianças da elite no Período Imperial no Brasil, segundo Mauad (2015), prevalecia um enaltecimento aos trabalhos manuais para as meninas, e intelectuais para os meninos, ou a possibilidade de vincular-se à carreira militar. Ao contrário, na fala de Shena encontramos a problematização das características com valentia, bravura e senso de aventura estarem ainda atreladas à masculinidade:

Eu sempre fui meio 'macho' [risos]. Para te confessar, eu sempre gostei de jogar futebol, eu sempre brincava de carrinho, porque minhas amizades perto da minha casa eram meninos, então eu jogava bolicas, e não virei homem por isso... (SHENA).

E, ao contrário também, a gente vê muito homem na cozinha, muito homem cozinhando, restaurante, cuidando de filho. Lá em casa acontece assim, meu marido fica em casa e toma conta das filhas, é ele que vai na reunião quando 
eu não posso, ele que toma conta delas, ele que... tudo, né? Dá banho... e eu que trabalho. (SHENA).

Essa mesma entrevistada problematiza os binarismos e explicita que os trabalhos domésticos e cuidado com os/as filhos(as) são de responsabilidade dos adultos. A divisão de tarefas domésticas, antes prerrogativas da mulher, é um sinal de mudanças em muitas esferas que compõem a sociedade. Isso significa que, em âmbito político, econômico, financeiro e, evidentemente, em âmbito familiar, há homens e mulheres que têm considerado romper o ciclo de perpetuação de práticas de desigualdade de gênero. A saída da mulher do restrito ambiente doméstico também teve importância no concernente ao cuidado e educação das crianças. Segundo Oliveira (2012), no início século XX, com o aumento da urbanização decorrente da industrialização, muitos movimentos operários reivindicavam melhores condições de trabalho nas fábricas. "Nesse clima, muitas mulheres, também contratadas pelas fábricas, começaram a se politizar e a exigir seus direitos, o que incluía a criação de locais para guarda e atendimento das crianças durante seu trabalho." (OLIVEIRA, 2012, p. 22). Em relação à diferenciação de gênero e sua repercusão na identidade sexual, observa-se na narrativa de uma professora:

Na verdade, senti na pele esta questão também... Minha filha tem de 24 anos, sempre gostou de futebol, carrinhos... meu marido também não aprovava... agora, se assumiu homossexual... No começo foi um choque, então busquei leituras... E agora, me pergunto: 'Que diferença faz?' Na verdade, isto é o que menos importa. (ATENA).

Diante dessa percepção, Finco (2003) assinala que a preocupação de que a identidade de gênero definirá posteriormente a identidade sexual da criança está relacionada à compreensão de que identidade sexual e de gênero estejam diretamente interligadas. Ainda, aliada a essa percepção, está a ideia de que, ao separar carros e bonecas para meninos e meninas, respectivamente, se está contribuindo para a construção da identidade de gênero.

\section{Binarismos nos brinquedos e brincadeiras}

Partindo do pressuposto que nas brincadeiras as crianças revivem e resignificam as representações e estereótipos do seu universo cultural, e aqui incluímos as representações generificadas, optou-se por investigar o modo como as professoras compreendem as relações que as crianças estabelecem nas brincadeiras, bem como a mediação realizada a partir da disposição e organização dos brinquedos. Durante a observação participante, ficou evidente que a seleção dos brinquedos e das brincadeiras estava orientada pelas diferenças de gênero. Na sequência, algumas narrativas que constituem e marcam a segregação dos corpos das crianças a partir de lugares diferenciados para meninos e meninas. Mesmo que se mudem as cores, a justificativa para que os grupos sejam separados em meninos e meninas continua por via de outros atributos, como identificação com o universo das princesas, por exemplo.

A sala é bem colorida, a única coisa em questão é o saquinho das escovas [risos], o das meninas é azul e o dos meninos é... não, dos meninos é azul e das meninas é rosa. [Preferência deles ou você fez e eles gostaram?] Eu fiz e eles gostaram, né! Não tem uma justificativa, na verdade as meninas sempre querem coisas de princesas e os meninos de azul, né. (LOLITA).

A maioria dos casos, os meninos gostam de brincar de carrinho, e a maioria das meninas gosta de brincar de boneca. Só que tem uma ou outra menina alí que gosta de brincar de carrinho também, e a gente nunca impede. (SHENA).

Nesse contexto, é importante compreender que a fila, a chamada, o mural de aniversariantes ou cartaz de ajudante do dia, a escolha sobre quem realizará cada atividade, a interação com os brinquedos é permeada pela divisão de papéis tradicionais de gênero, como também parece habitual o uso de expressões populares como: "comporte-se como uma mocinha" ou "menino não chora" e, ainda, que sejam oferecidas bonecas e miniaturas de utensílios 
domésticos para as meninas e jogos de montar, bonecos de super-heróis e carrinhos para o grupo de meninos, naturalizando, desta forma, lugares, espaços e comportamentos binários para cada gênero.

Nessa direção, referenciamos as contribuições de Finco, Gobbi e Faria (2015), ao problematizarem o papel da educação de meninas e meninos realizada pela instituição de Educação Infantil, questionando os processos da construção dessa diferenciação ao longo dos cursos de formação. Essas reflexões nos permitem criar práticas educativas não discriminatórias, que possibilitem a igualdade de gênero desde a primeira infância. Portanto, segundo essas autoras, a formação acadêmica e continuada ainda se torna insuficiente no que diz respeito ao debate acerca da diversidade e das questões de gênero, pouco observadas nas creches e pré-escolas.

Segundo Finco (2003, p. 98), se a professora não reflete sobre o seu papel social nas interações entre meninos e meninas, “[...] ela pode organizar a brincadeira de uma forma a favorecer o sexismo, a prática da professora pode fazer com que as crianças se organizem em grupos distintos de meninas e meninos, sem que haja uma ordem explícita para isso". No período de observação, constatamos que, muitas vezes, o excesso de tarefas atribuídas às professoras da pré-escola impede maior percepção das relações entre meninos e meninas. 0 momento das brincadeiras geralmente é aproveitado para antecipar escritas na agenda, recortar lembrancinhas, organizar as mesas e colchões. Segundo Angotti (2000), devido a esse distanciamento, existe uma significativa perda da possibilidade de reconhecer os conhecimentos elaborados pelas crianças, que enriquecem o fazer pedagógico, inclusive quando trazem concepções que não os permitem transitar, conhecer todos brinquedos e cores, independentemente do significado dado culturalmente, como se pode observar nas falas a seguir:

No outro dia, resolvi mudar: 'Eu vou dar rosa para todo mundo.' Foi aquela polêmica: 'Ai, pro- fessora, eu não quero rosa.' Aí fui lá eu explicar que meninos também usam rosa e meninas azul, mas eles sempre ficam indagando, né, porque eles estão usando rosa, porque prato rosa é de menina. Na concepção deles é isso, né! (ANITA).

Sim, até a gente fez uma atividade a respeito da higiene, daí todos tinham que trazer uma boneca ou um boneco, daí o que acontece... Os pais: 'Ah! Ele não tem boneca.' 'Então traz um boneco para dar banho.' Daí eles sempre indagando, assim, por que o menino tem que trazer a boneca para dar banho. Daí tive que conversar com os pais também, quando eles crescerem eles não vão ter aquele impedimento para ajudar a mãe em casa. Daí foi uma atividade bem interessante, eles deram banho nas bonecas. (ANITA).

De vez em quando eles falam, né, tem esta questão de brincadeira, aí, o amigo está brincando com boneca. Mas ali a gente conversa que, quando, no interior... ali com as crianças a gente fala que isto é normal, que dá para brincar, que não tem nada a ver. Eu falo a mesma coisa para o pai. (LOLITA).

[...] assim, na verdade, quanto às cores e brinquedos, eu vivencio no meu ambiente familiar, meu filho adora bonecas. Meu marido, muito machista, reprime, e tenho que estar intervindo, explicando. (ATENA).

Conversando com as crianças acerca de suas preferências por bonecas e carrinhos, alguns meninos disseram não brincar de boneca porque a mãe não compra ou o pai não deixa. Finco (2003), em seus estudos sobre gênero e educação infantil, alerta sobre as mediações do adulto para a construção de uma cultura sexista que, de certa forma, normaliza comportamentos. Nessa mesma direção, encontramos nos documentos legais referências a valoração e reconhecimento das diferenças concernentes ao meio do qual as crianças são oriundas, do viver em famílias distintas, da proveniência de comunidades étnicas, ambientes culturais e níveis econômicos diversos (BRASIL, 2012). Sobre as relações estabelecidas com as famílias, Bragagnolo e Wiggers (2014) argumentam que as diferentes formas de organização familiar apresentam valores e princípios distintos, todavia, bastante comuns a todas as famílias, 
devido ao fato de que é atribuída à mulher a responsabilidade pelo cuidado e saúde dos filhos.

0 contexto familiar da criança, segundo Barbosa (2009), é uma ferramenta importante na desconstrução das desigualdades de gênero, envolvendo uma estreita ligação de confiança entre professor(a), criança e família. Para tanto, essa autora pontua a indispensabilidade das famílias nas reuniões pedagógicas, propiciando uma reflexão acerca da responsabilidade compartilhada e do fomento aos sentimentos que despertem o respeito às diferenças. Na fala das entrevistadas, percebemos que não há uma organização de espaço e tempo que propicie este diálogo com as famílias. Na maioria das vezes, as conversas ocorrem informalmente a partir de situações e demandas individuais.

\section{Binarismos nos modos de organização dos corpos nos espaços educativos}

Durante a pesquisa, observamos, em muitos momentos, as crianças falando "aqui é lugar das meninas" ou "é lugar de meninos". Nessas ocasiões, não houve interferência das professoras, então passamos a nos perguntar o que pode significar esse silêncio. Nessa direção, Louro (2014) considera importante perceber os gestos, as falas e os silêncios presentes no cotidiano escolar.

0 olhar precisa esquadrinhar as paredes, percorrer os corredores e salas, deter-se nas pessoas, nos seus gestos, suas roupas; é preciso perceber os sons, as falas, as sinetas e os silêncios; é necessário sentir os cheiros especiais; as cadências e os ritmos marcando movimentos de adultos e crianças. (LOURO, 2014, p. 63).

Para Tamanini (2009), nos espaços educacionais se desenvolve um currículo oculto, sendo este muitas vezes despercebido. Por currículo oculto entenda-se um corpus cultural que é passado, subjetivamente, de modo consciente ou inconsciente, em cada atividade, em cada fala, em cada elogio ou reprimenda, em cada olhar ou comentário, direcionado a todas as crianças ou para cada uma delas de maneira específica. A partir desse currículo oculto, dessa lista que existe, mas não é escrita, os discursos são subjetivados por meninos e meninas que se diferenciam por comportamentos, gestos, roupas, brinquedos etc.

Observamos na alimentação as implicações desses aprendizados que podem ser nomeados como currículo oculto. 0 deslocamento para o refeitório é organizado por filas separadas, de meninos e meninas. No momento da higiene, meninos e meninas utilizam o banheiro em duplas, novamente separados. As brincadeiras no parque têm horários estabelecidos para as turmas e os brinquedos (fantasias, carrinhos e bonecas, baldinhos de areia, bolas, bambolês) são distribuídos em horários distintos. Quando as entrevistadas foram questionadas a respeito das filas, relataram o seguinte:

Eu coloco em fila [risos], meninas e meninas separados. Separadinhos, meninas de um lado, mas por uma questão, sei lá... Sabe que eu não sei por que eu trabalho, mas eu acho bonitinho, fica ali separadinho, certinho. Eu sempre fiz, desde o início. Acho que quando eu já comecei a fazer estágio, eu vi as professoras, ah!, fazendo, e eu fiz assim também. (LOLITA).

Geralmente, nos lugares que precisam ir todos juntos, vamos em filas, meninas e meninos separados [...] apesar que eles sempre dão as mãos para a menina ou o menino da fila ao lado. (ATENA).

Separado, a maioria das vezes separado, meninos e meninas... Então, para não dar muito, assim, fazerem muita bagunça, a gente vem cantando, ou às vezes: 'Ah! Passinhos de formiga, passinhos de elefante', para não virem se jogando, né [risos]. Às vezes eu coloco todos juntos, com a mãozinha no ombro, assim, para mudar um pouco [...] (ANITA).

Cabe lembrar que a Proposta Curricular de Santa Catarina (PCSC) de 2014 (SANTA CATARINA, 2014) enfatiza a brincadeira como atividade curricular, momento em que jogos e brincadeiras de faz de conta são concebidos 
como elementos indispensáveis ao desenvolvimento humano. Na concepção explícita nesse documento, "Essa atividade não perde sua importância para o desenvolvimento da criança quando ela, aos seis anos, ingressa no Ensino Fundamental." (SANTA CATARINA, 2014, p. 40).

Além da importância da brincadeira para o desenvolvimento da criança, o Manual de Orientação Pedagógica elaborado por Kishimoto e Freyberger (2012) aponta a brincadeira como forma de a criança vivenciar princípios éticos no momento da discussão das regras, quando aprende sobre o respeito ao lugar do outro e quando compreende a importância de esperar sua vez. Nas brincadeiras de faz de conta ou naquelas consideradas típicas, ressalta-se a importância de promover situações com o objetivo de favorecer a identidade e a diversidade cultural.

No interior das salas do Centro de Educação Infantil observou-se cores diferenciadas para meninos e meninas, filas separadas por gênero, lugares pré-determinados nas mesas. Grande parte das professoras, apesar de não atribuirem papéis perante os brinquedos e brincadeiras, ainda têm interiorizadas cores e certos comportamentos adequados para meninos e para meninas. Uma das entrevistadas demonstrou preocupação em mesclar, ou melhor, intercalar as crianças, colocando uma menina e em seguida um menino para dormir com o intuito de controlar os corpos.

Geralmente peço para intercalar um menino e uma menina, um menino e uma menina, e assim por diante... É que, na verdade, quando deixava livre escolha não deu muito certo, os meninos se agitavam demais e começavam as lutinhas [risos]. Fiz assim e funcionou. (ATENA).

Nesse regime, também mostra Carvalho (2014) que são nas ações do cotidiano que, geralmente, se reproduz o modo de controle social, como um princípio organizador do currículo e das práticas educacionais. "O gênero funciona como um princípio de organização da ordem social e continua sendo usado como um princípio organizador do sistema, da institui- ção, das práticas curriculares e pedagógicas da Educação Infantil." (CARVALHO, 2014, p. 436). As práticas de cuidados corporais das crianças podem promover separações ou misturas de sexo ou gênero, como, por exemplo, o banho e o uso do banheiro, momentos importantes na demarcação de espaços e gêneros.

A escola, nesse sentido, segundo Graupe (2014), deve possibilitar que meninos e meninas sejam respeitados e distanciados de estereótipos de gênero e papéis sexuais tradicionais. Diferente de uma escola conteudista, o desenvolvimento social e afetivo é valorizado. Os princípios de uma educação igualitária, propostos pela pedagogia da equidade, proporcionam um questionamento acerca das desigualdades de sexo presentes, muitas vezes, em histórias e demais práticas cotidianas.

Enfim, uma escola poderá desenvolver a sua proposta pedagógica na perspectiva da pedagogia da equidade somente, se ela primeiramente, vivenciar internamente os princípios da democracia, direitos iguais, a capacidade de dialogar com os seus diversos segmentos de forma ética e justa. (GRAUPE, 2014, p. 406).

Nesse contexto, a função social da professora é fundamental no processo de desconstrução e construção de uma maneira diferente de compreender e interagir com o outro e consigo mesmo. 0 que se quer enfatizar, portanto, é que a mudança não se dá rapidamente, porque não ocorre na superfície das relações sociais. Não se trata de modificar o discurso, nem de investir em uma mudança que, comumente, permanece restrita nas aparências. Evidentemente que organizar de forma diferente os espaços e tempos torna-se fundamental para uma pedagogia que preze pela igualdade de gênero.

\section{Considerações finais}

Refletir sobre as brincadeiras na Educação Infantil na perspectiva da equidade de gênero nos permitiu constatar que as brincadeiras são momentos importantes para a desconstrução das desigualdades de gênero na infância. 
Em primeira mão, um convite a pensar, a olhar sob outro ângulo os binarismos, o modo como nos relacionamos com as crianças e, sobretudo, pensar como as brincadeiras das crianças são expressões/linguagens potentes de mediações pedagógicas. Nesta pesquisa, a partir da narrativa das professoras, podemos refletir acerca da necessidade de um olhar, uma mirada, atento às relações que as crianças estabelecem nas brincadeiras, por envolver compreensões de gênero e, principalmente, refletir para além da separação dos corpos. As professoras apontam em suas narrativas a existência de binarismos sobre gênero e brincadeiras: binarismos atribuídos à diferenciação de meninos e meninas, binarismos nos brinquedos e brincadeiras e binarismos nos modos de organização dos corpos nos espaços educativos.

0 reconhecimento de que as brincadeiras na prática cotidiana da Educação Infantil são fundamentais na construção da identidade da criança, na construção de valores, de respeito, nos permitiu identificar relações excludentes ao eleger e naturalizar lugares binários e fixos para meninos e meninas, sejam eles atrelados a cores, a características subjetivas, a modos de separar seus corpos, considerando as dimensões das relações sociais e diferenças de gênero. É importante pensar a brincadeira como uma ação que permite à criança fazer suas escolhas. Contudo, não se pode negar que professoras(es) e adultos familiares geralmente trazem consigo alguns conceitos naturalizados em contextos socioculturais, permeando dificuldades e barreiras na ação pedagógica e educativa, como, por exemplo, a ideia de que meninos não devem brincar de boneca para não virarem gays.

Percebe-se, com isso, que o brincar se constitui como uma experiência na qual a criança vivencia o mundo, exercendo seus direitos e sua cidadania enquanto aprende a respeitar e valorizar a diversidade. Por meio das vivências e brincadeiras, as crianças que frequentam a
Educação Infantil têm oportunidade de se relacionar com adultos e com outras crianças, o que se constitui como experiência formativa dos sujeitos, vindo a contribuir para uma convivência pautada no respeito à diversidade humana. Entretanto, quando a ação da professora da Educação Infantil é balizada apenas pela consciência da necessidade de cuidado e proteção, são perdidas muitas oportunidades de realizar uma prática pedagógica transformadora, capaz de promover o desenvolvimento integral da criança. Há uma tendência em manter a ordem, em priorizar o silêncio e o pouco movimento, esquecendo-se que a docência e o aprendizado implicam em interação, diálogo e brincadeira.

É pertinente enfatizar a relevância das discussões sobre gênero em âmbito educacional, tanto nos espaços próprios de formação docente, como nos demais espaços que compõem as instituições de Educação Infantil. Aos profissionais da educação, compreender a questão da desigualdade de gênero, bem como o conceito de gênero em si, representa a concreta possibilidade de minimizar condutas bem intencionadas, mas impregnadas de preconceito e desrespeito à diversidade. Além disso, tais diálogos promovem reflexões fundamentais no processo de docência em si, já que podem representar mudanças no modo de pensar e compreender as relações de gênero em sua própria prática pedagógica.

Enfim, nas brincadeiras, observou-se que, se a professora fizer uso das reflexões sobre gênero e educação, estas podem servir como ferramenta/instrumento de problematização de estereótipos tradicionais de gênero (cor azul para menino, menino não chora, menina é princesa, delicada, submissa) e, ainda, se tornarem momentos de reflexão, de desconstrução de desigualdades e da ludicidade, quando as crianças podem transitar e brincar com liberdade. Liberdade de pensar, de se mover, de sentir, de ser criança livre de estereótipos tradicionais de gênero e, por consequência, livre de violências de gênero. 


\section{REFERENNCIAS}

ANGOTTI, M. Semeando o trabalho docente. In: OLIVEIRA, Z. M. R. de (org.). Educação Infantil: muitos olhares. 4. ed. São Paulo: Cortez, 2000. p. 51-68.

BARBOSA, M. C. Práticas cotidianas na educação - bases para reflexão sobre as orientações curriculares. Brasília, DF: MEC, 2009. Disponível em: http://portal.mec.gov.br/dmdocuments/ relat_seb_praticas_cotidianas.pdf. Acesso em: 01 out. 2019.

BARROS, A. J. S. Fundamentos da metodologia científica. 3. ed. São Paulo: Pearson Prentice Hall, 2007.

BRAGAGNOLO, R. I.; WIGGERS, V. Reflexões sobre o lugar da primeira infância na creche e na pré-escola. In: ASSIS, G. O.; MINELLA, L. S.; FUNCK, S. B. (org.). Entrelugares e mobilidades: desafios feministas. Tubarão: Copiart, 2014. p. 439-468.

BRASIL. Presidência da República. Casa Civil. Constituição da República Federativa do Brasil de 1988. Brasília, DF, 1988. Disponível em: http:// www.planalto.gov.br/ccivil_03/constituicao/ constituicao.htm. Acesso em: 22 set. 2019.

BRASIL, Ministério da Educação. Secretaria de Educação Básica. Diretrizes Curriculares Nacionais para a Educação Infantil. Brasília, DF: MEC/SEB, 2010. Disponível em: http:// portal.mec.gov.br/index.php?option $=$ com $_{-}$ docman \&view =download \&alias $=9769$ diretrizescurriculares- $2012 \&$ category slug=janeiro-2012-pdf\&Itemid=30192. Acesso em: 22 fev. 2019.

BRASIL. Governo Federal. Presidência da República: Secretaria de Políticas para as Mulheres. Orientações estratégicas para institucionalização da temática de gênero nos órgãos governamentais. Brasília, DF: Comitê de Articulação de Monitoramento do Plano Nacional de Políticas para as Mulheres, 2011.

BRASIL. Ministério da Educação. Secretaria de Educação Básica. Brinquedos e brincadeiras nas creches: manual de orientação. Brasília, DF: MEC/ SEB, 2012.

BRASIL. Presidência da República. Casa Civil. Lei no 13.005, de 25 de junho de 2014. Aprova o Plano Nacional de Educação - PNE e dá outras providências. Brasília, DF, 2014. Disponível em: http://www.planalto.gov.br/ccivil_03/_ato2011- 2014/2014/lei/l13005.htm. Acesso em: 22 set. 2019.

BUTLER, J. Problemas de gênero: feminismo e subversão de identidade. Rio de Janeiro: Civilização Brasileira, 1990.

CAMPOS, R.; BARBOSA, M. C. S. BNC e educação infantil: quais as possibilidades? Retratos da Escola, Brasília, DF, v. 9, n. 17, p. 353-366, jul./dez. 2015. Disponível em: http//www.esforce.org.br. Acesso em: 22 fev. 2019.

CARREIRA, D. (Coord.). Informe BRASIL - Gênero e Educação. São Paulo: Ação Educativa, 2011.

CARREIRA, D. Gênero e educação: fortalecendo uma agenda para as políticas educacionais. São Paulo: Ação Educativa/Cladem/Ecos/Geledés/ Fundação Carlos Chagas, 2016.

CARVALHO, M. E. P. Construções e desconstruções de gênero na instituição de educação infantil. In: ASSIS, G. O.; MINELLA, L. S.; FUNK, S. B. (org.). Entrelugares e mobilidades: desafios feministas. Tubarão, SC: Copiart, 2014. p. 427 a 438.

FINCO, D. Relações de gênero nas brincadeiras de meninos e meninas na Educação Infantil. Pró-Posições, v. 14, n. 42, p. 89-101, set./dez. 2003.

FINCO, D.; GOBBI, M. A; FARIA, A. L. G. Creche e feminismo: desafios atuais para uma educação descolonizadora. Campinas, SP: Leitura Crítica/ Associação de Leitura do Brasil (ALB); São Paulo: Fundação Carlos Chagas (FCC), 2015.

FLICK, U. Codificação e categorização. In: FLICK, U. Introdução à pesquisa qualitativa. 3. ed. Tradução: Joice Elias. Porto Alegre: Artmed, 2009. p. 276-297.

GRAUPE, M. E. Pedagogia da equidade: gênero e diversidade no contexto escolar. In: MINELLA, L. S.; ASSIS, G. O.; FUNK, S. B. (org.). Desafios feministas. Tubarão, SC: Copiart, 2014. p. 389-410.

KISHIMOTO, T. M. (org.). Jogo, brinquedo, brincadeira e educação. São Paulo: Cortez, 2008.

KISHIMOTO, T. M.; FREYBERGER, A. Brinquedos, brincadeiras e materiais para bebês: manual de orientação pedagógica: Módulo II. Brasília, DF: Ministério da Educação Básica, 2012.

KRAMER, S. A política do pré-escolar no Brasil: a arte do disfarce. 9. ed. São Paulo: Cortez, 2011.

LOURO, G. L. Gênero, sexualidade e educação: uma perspectiva pós-estruturalista. 16. ed. Petrópolis, RJ: Vozes, 2014. 
MAUAD, A. M. A vida das crianças de elite durante o Império. In: DEL PRIORE, M. História das crianças no Brasil. 7. ed, $2^{2}$ reimpr. São Paulo: Contexto, 2015. p. 137-176.

MAYRING, P. Qualitative inhaltsanalyse. In: FLICK, U.; KARDOFF, E.V.; STEINKE, I. (org.). Qualitative forschung: Ein Handbuch. Reinbeck: Rowohlt. S., 2007. p. $468-475$.

MEIRELLES, R. Território do brincar: diálogo com escolas. São Paulo: Instituto Alana, 2015.

OLIVEIRA, Z. R. 0 trabalho do professor na educação infantil. São Paulo: Biruta, 2012.

RAMOS, F. P. A história trágico-marítima das crianças nas embarcações portuguesas do século XVI. In: DEL PRIORE, M. História das crianças no Brasil. 7. ed, 2a reimpr. São Paulo: Contexto, 2015. p. 19-54.

REIS, T.; EGGERT, E. Ideologia de gênero: uma falácia construída sobre os planos de educação brasileiros. Educação e Sociedade, Campinas, SP, v. 38, n. 138, p. 9-26, jan. 2017. Disponível em: http://www.scielo.br/scielo.php?script=sci arttext\&pid=S0101-73302017000100009\&lng=e n\&nrm=iso. Acesso em: 06 out. 2019.
ROUSSEAU, Jean-Jacques. Emílio, ou da educação. Tradução por Sérgio Milliet. 3. ed. Rio de Janeiro: Bertrand Brasil, 1995.

SANTA CATARINA. Governo do Estado. Secretaria de Estado da Educação. Proposta Curricular de Santa Catarina: formação integral na educação básica. Florianópolis, 2014.

SCOTT, Joan. Gênero: uma categoria útil de análise histórica. Educação e Realidade, Porto Alegre, v. 20, n. 2, p. 71-99, jul./dez. 1995.

TAMANINI, M.; SANTOS, S. F. dos; BONA SARTOR, G. E. Gênero, sexualidade e relações étnicoraciais: limites e desafios de um curso a distância. In: MINELLA, L. S.; CABRAL, C. G. (org.). Práticas pedagógicas e emancipação: gênero e diversidade na escola. Florianópolis: Mulheres, 2009. p. 67-92.

VIANNA, C. A mente do bebê: o fascinante processo de formação do cérebro e a personalidade, 3. ed., ver. e atual. São Paulo: Dueto Editorial, 2011.

VIANNA, C.; UNBEHAUN, S. O gênero nas políticas públicas de educação no Brasil: 1988-2002. Cadernos de Pesquisa, v. 34, n. 121, p. 77-104, jan./ abr. 2004. 